\title{
Impact of Affirmative Action in Higher Education for the Other Backward Classes in India
}

\section{Rakesh Basant \\ Gitanjali Sen}

\section{W.P. No. 2016-07-01}

July 2016

The main objective of the working paper series of the IIMA is to help faculty members, research staff and doctoral students to speedily share their research findings with professional colleagues and test their research findings at the pre-publication stage. IIMA is committed to maintain academic freedom. The opinion(s), view(s) and conclusion(s) expressed in the working paper are those of the authors and not that of IIMA.

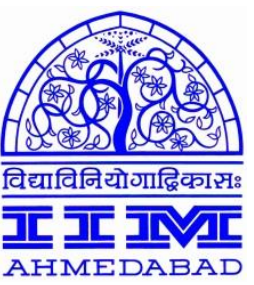

\section{INDIAN INSTITUTE OF MANAGEMENT \\ AHMEDABAD-380 015 \\ INDIA}




\title{
Impact of Affirmative Action in Higher Education for the Other Backward Classes in India ${ }^{1}$
}

\author{
Rakesh Basant ${ }^{2}$ \\ Indian Institute of Management, Ahmedabad, India

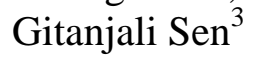 \\ Shiv Nadar University, India
}

\begin{abstract}
This paper measures the impact of quota-based affirmative action in higher education (HE) in India for Other Backward Classes (OBC), implemented from 2008. Since the immediate impact would be felt by OBCs who were eligible to go to college at the time of the implementation, we compare the differences in participation in HE by the younger (18-23 years) and the older (24-29 years) age groups within eligible OBCs, with similar differences in the general caste population. The same double difference is also compared across states with different histories of affirmative action to ascertain if there are regional variations in the impact of the policy, with the expectation that the impact would be higher in regions with no history of affirmative action. Our results from the Difference in Difference (DD) estimates based on National Sample Survey data for 2011-12 do not show a positive impact of the policy on the participation of OBCs. In fact, the impact seems to be negative in all regions, though statistically insignificant, except the East which lacks the long history of affirmative action. A comparison of the East without a long history of affirmative action with the South having a long history of such policy, using triple difference method, produces positive treatment effects, but the estimate loses statistical significance once we control for observable covariates. Our results suggest that the generalized nation-wide policy of this kind may not be relevant for issues which are more regional in nature. (JEL Codes: H75, I23, I24, I25, I28, J15, O15).
\end{abstract}

Key words: Higher education, affirmative action, caste, reservations, India.

\footnotetext{
${ }^{1}$ Both authors acknowledge the Indian Institutions of Management, Ahmedabad, India, for financial support. The authors also acknowledge the excellent research assistance of Rakesh Sinha for extraction of the National Sample Survey (NSS) data. However, all errors rest with authors.

${ }^{2}$ Indian Institute of Management, Ahmedabad, India.

${ }^{3}$ Corresponding author, \#E383, Shiv Nadar University, UP, India, Pin 201314. Email: gitanjali.sen@ snu.edu.in, gitan_dutta@hotmail.com
} 


\section{Introduction}

Affirmative actions, through positive discrimination policies in employment and education domains have been in place around the world for close to a century (Sowell 2004), and have always been a matter of debate, leading to wide variations in policies and implementation across nations (Cunningham, 2001). In India, the implementation has been one of the oldest; although initially through few fragmented initiatives, that date back to several decades before the formation of the Indian republic (Osborne 2001, Zwart 2000). Without the support of any nationwide mandate, affirmative action was being practiced more in certain parts of country, particularly in the four southern states of Tamil Nadu, Kerala, Karnataka, and Andhra Pradesh ${ }^{4}$. The policy received constitutional support for the specific groups, namely, Schedules Castes (SC), Scheduled Tribes (ST) in the year 1950. The primary target of this policy was to encourage higher participation of the historically disadvantaged groups, initially in employment; later extended to education and political domains.

Although, the quota for the SCs and STs in both the education and employment domains in India have been present from the beginning of the state formation, the reservations for the Other Backwards Classes (OBCs) started much later. Unlike the SCs and STs, the OBCs were not formed from any homogeneous set of caste groups, but it was a list of groups to be decided by the center or the states, based on their status on being historically disadvantaged (Deshpande 2011). In the year 2008, the Central Educational Institutions (Reservations in Admissions) Amendment Bill was passed in Indian parliament, recommending the implementation of the

\footnotetext{
${ }^{4}$ Throughout this study, the above four states are referred as southern states. The state of Andhra Pradesh includes the recently formed state of Telangana as well.
} 
Central Educational Institutions (Reservations in Admission) Act, 2006 from the year 2008 ${ }^{5}$. The Act requires 27 percent reservations of seats for OBC students in public funded institutions of higher education in the country, to be implemented in a phased manner across India. The bill was amended in the year 2012 again, with a guideline to complete the implementation by the year 2014. In addition to this federal mandate, certain state-governments continued their own reservation policies, as was being practiced even before the year 2008. The private educational institutions, minority institutions, and few institutions of national importance, as declared by the government of India, still remain outside the purview of this nationwide caste based reservation policy.

Since the implementation of the $\mathrm{OBC}$ quota in the centrally funded institutions, the issue of whether the percentages reserved for OBCs in institutions of higher education actually underrepresents or over-represents the share of OBCs in total population, has cropped up frequently . Questions have also been raised regarding the uniformity in the lists of castes considered as OBCs across states of India. The most recent cabinet decision of inclusion of Jats in the list of OBCs (Ghildiyal 2014) just before the nationwide parliamentary election in the year 2014, indicates the importance of caste-based reservation policy in Indian politics, and the political weightage of interest groups (Osborne 2001). Interestingly, majority of the Jat population resides in the states of Uttar Pradesh, Uttarakhand, Rajasthan, Haryana, and parts of Madhya Pradesh and Gujarat, constituting the power lobby of Indian politics and a significant share of electoral seats. Following the recommendation of the Ministry of Human Resource Development, from the year 2008-09, Government of India has allocated additional funds to the tune of Rs. 21,668.9

\footnotetext{
${ }^{5}$ The Central Educational Institutions (Reservations in Admission) Act, 2006 and consequent amendments to the Act can be found at http://www.judis.nic.in/ accessed on $1^{\text {st }}$ May, 2014.
} 
million to the central universities and Rs. 42,274.6 million to the centrally funded technical institutions for a 54 percent capacity expansion in each central institution. This was done to implement the policy of OBC reservations, without cutting down general category seats.

The present paper attempts to measure the impact of the new legislation, the Central Educational Institutions (Reservations in Admissions) Amendment Bill, 2008 (henceforth, the Act) on educational participation of the OBCs. However, the Act being very recent, we have data for only one period after the implementation, which is the year 2011-12. We begin with the premise that the impact of the legislation would be felt by OBCs who were eligible to go to college at the time of the implementation of the Act. Typically, these persons would be in the age cohort of 1823 years in 2011-12; participation of persons of the older age group would not have been affected by the Act. To assess the impact of the Act, we use the data for this year to make two types of comparisons: (1) compare differences in participation in HE by the younger (18-23 years) with the participation of older age cohort (24-29) within OBCs with differences in the general caste population; and (2) compare the second difference across states with different histories of affirmative action to ascertain if there are regional variations in the impact of the Act as we expect the impact to be higher in regions with no history of affirmative action. Difference in Difference estimates (DD) are used to measure the Intent-to-treat effect (ITT) on the basis of the first comparison. DD analysis is done separately for different regions for the second comparison. An attempt is also made to measure the ITT effect of the Act through a triple difference (DDD) estimation strategy by exploiting the variation of implementation across states of India. 
Our results do not show a positive impact of the Act on the participation of OBCs. In fact, the participation of the general population has increased faster than that of OBCs in the relevant age group after the implementation of the Act. For the full sample consisting of all regions, our estimates indicate that the positive difference between the treated (18-23 years) and control (2429 years) cohort of OBCs are less than the positive difference of the same among general population indicating a 0.04 point less age-relevant enrolment of OBCs than general population, even after the affirmative action. However, when we conduct the analysis separately for selected regions, we do not find a statistically significant effect on participation of OBCs in higher education in any of the four regions, but the effects seem to be negative in sign in all regions except for the East. Since the Eastern region is the one with no history of affirmative action, this result is consistent with our a priori expectations. Following these positive effects in the Eastern region, when we use the quasi-experimental estimation strategy (using triple difference method) to compare Southern region (non-experimental with long history of affirmative action) with Eastern (experimental with no history), we find positive treatment effects indicating a positive impact of the Act on OBC participation in states with no history of affirmative action. However, the estimate loses statistical significance once we control for observable covariates but the coefficient remains positive which may be credited to the Act.

There has been simultaneous expansion of higher education institutions across the country, but that is not expected to bias our estimates because that is supposed to affect both the OBCs and general population, and of both cohorts, in similar manner.

To our knowledge this is the first study attempting to measure the causal impact of nationwide affirmative action policy in India. The complexity of caste based affirmative action in a nation 
where educational policies are both state and federal subject is addressed throughout the paper. Affirmative action policies in different domains being an increasingly popular policy issue globally, the simplified research design of this paper can be further suited to the specific geographic location or domain.

The rest of the paper is organized as follows. Section 2 discusses the history of reservation polices in India, issues, context and relevant literature. Section 3 explains the data and empirical strategy. Section 4 discusses the major findings of this paper. Section 5 concludes with policy recommendation.

\section{Issues, Context and Contribution to Literature}

\subsection{History of Reservations in India}

Reservations in India date back to early nineteenth century. The British Indian Government implemented a policy of reserving places for Muslims in Indian educational institutions in the year 1882 (Hunter Commission). But during that period the reservation was not specifically designed for any particular group, caste, religion or ethnicity and therefore, was not based on the representation of any group in total population; rather, it was only meant to provide equal opportunity. The caste based reservations for the SCs and the STs across few Indian states started in the year 1935, with the operation of the 'Pune pact' between Mahatma Gandhi and B R Ambedkar. With the landmark decision of honorable Supreme Court of India in 1963, it was mandated that reservations in any institution could not exceed the quota of 50 percent (Kaur and Suri 2009, pp 113). The 93rd amendment of the constitution of India also mandated a maximum 
of 50 percent seats that could be reserved for this purpose, in state and centrally funded institutions of higher education.

States of Tamil Nadu and Karnataka started implementing reservations policy for OBCs through quota in the 1970s (Baely 1999). The distinction between the southern part of India and the northern part may be noted in this respect (Kumar 1992). Historically, caste discrimination has been worse in south India, as in certain parts of Bengal and northern India. Even though nonBrahmins $^{6}$ were placed in government jobs, it was almost impossible in southern part of India in absence of reservation policies.

Apart from the four southern states, reservations for OBCs have been in place in varying degrees in some north-central states. The OBC reservations started in a very slow and fragmented manner during late seventies and eighties in the north-central states of Gujarat, Rajasthan, Maharashtra, Bihar, Uttar Pradesh, Punjab, Haryana and Himachal Pradesh (Parikh 2001) ${ }^{7}$. In the eastern states of West Bengal, Orissa, Assam, and in most of the north-eastern states ${ }^{8}$, reservations for $\mathrm{OBCs}$ barely existed due to the nature of the historical evolution of the caste pattern. After the federal government handed over the responsibility of exploring the status of OBCs in the country to a commission (known as Mandal commission), it came up with the recommendation of about 27 percent reservation of seats in employment and education domains in the year 1981. However, due to a huge debate on this issue, followed by nationwide protests,

\footnotetext{
${ }^{6}$ Brahmins refer to the most upper castes among Hindu society.

${ }^{7}$ The state of Bihar includes Jharkhand, and the state of Uttar Pradesh includes Uttarakhand, as both states were curved out in first decade of $21^{\text {st }}$ century, and NSS data can only identify them from 2004-05 onwards.

${ }^{8}$ Comprising of the states of Arunachal Pradesh, Nagaland, Manipur, Mizoram, Tripura, and Meghalaya.
} 
the implementation happened much later. In the year 1992, a reservation of 27 percent seats in public sector employment was implemented.

\subsection{Issues in Implementation}

A major issue about caste based reservation in India that complicates the process of implementation further is, the list of castes designated as the OBCs are prepared separately at the central and the state level. Hence, certain castes scheduled as OBCs for the purpose of central government jobs, may not be listed as OBCs in state government jobs (Galanter, 1984).

The primary argument for this kind of 'positive discrimination' through quota for a certain historically disadvantaged section of society is to encourage participation in higher education. In fact, some studies show that participation of backward classes has actually increased over years (Azam and Blom, 2008). However, the studies do not establish causality to show that the increased participation was indeed an effect of 'positive discrimination' policy. The estimates of participation of both the stock and flow measures, using the 61st round of the National Sample Survey (NSS) data (Basant and Sen 2010), indicate that an appropriate measure of deficit may change the debate around affirmative action towards the issue of supply side constraints. Using the NSS data of last one decade, Basant and Sen (2014a) show that the overall hierarchy of participation has not changed over years but convergence can be seen if appropriate measures are used. Due to the complexities in implementation of the reservation policies in its current form, they also argue that parental education can be used as a criterion for affirmative action (Basant and Sen, 2014b). 
To measure the impact of a program of reservation of seats for the OBCs at the state funded institutions of higher education that is implemented throughout the country at a specific point of time, is difficult. The fact that only a few years have elapsed since the program roll-out, adds to the difficulty in measuring the impact.

\subsection{Relevant Literature and Hypothesis Generation}

The literature in this area is mostly limited to discussions of the eligibility of the OBCs, or even SCs, STs as a group to receive such positive discrimination (Rao \& Ramchander 1982, Thorat et al 2016), or the rationales for extension of reservation policies to private sectors (Bertrand et al 2010). A recent study by Bagde et al (2016) measures the causal impact of the affirmative action policy in India for all the social groups, using data from one engineering college. It also lists some similar studies across the world. However, this most recent addition in affirmative action targeting the $\mathrm{OBC}$ in India is yet to be evaluated. Apart from few studies to document the progress of these disadvantaged groups over years (Basant and Sen 2014b), there is no study available in public domain that evaluates the causal impact of such policy at the national level.

The challenges involved in such an exercise are many. One, in India, education being a state subject as well, reservations for $\mathrm{OBC}$ in higher education have existed at varying degrees for different periods of time across different states of India. So, even if the nationwide law applies from the year 2008-09 onwards, finding a suitable counterfactual for identification of the program effect is a challenge. Second, the impact of such an Act on participation can take time as in higher education neither demand, nor supply is generated overnight. With the passage of time, the Act should also encourage supply side expansions of institutions to meet the higher demand that gets generated due to the policy change. The supply side expansion affects the 
higher enrolment too. So, it is important to dis-entangle the direct impact of the Act on enrolment and its indirect effect through the supply side expansion.

Given the differences in the histories of affirmative action for OBCs across Indian states and the differential supply of higher education institutions (HEIs), it is difficult to conceptualize and meaningfully estimate the impact of $\mathrm{OBC}$ reservation. We start with the premise that the immediate effect may take the form of higher enrolment of OBCs in HEIs. Since we are analysing a short time period which follows the announcement of the reservation policy, this is the only effect we can meaningfully estimate. Besides, this effect would be limited to only those in the relevant age cohort among the $\mathrm{OBC}$ population who are eligible to go to college, i.e., those who have crossed the school threshold. In the long run, such an affirmative action can potentially create incentives for $\mathrm{OBCs}$ to cross the school threshold to become eligible to join a HEI. Given this context, the following hypothesis can be postulated:

Hypothesis 1: Affirmative action for the OBCs will result in faster growth (or a lower decline) of enrolment of eligible OBCs in HEIs than the enrolment of eligible population not benefiting from affirmative action.

It needs to be noted only if $\mathrm{OBCs}$ do not experience a faster growth or lower decline than those who are not benefiting from quotas, the change may simply reflect trends in overall participation rates which are not caused by the policy intervention. 
Further, these impacts may vary by states. The impact in states with a long history of affirmative action in the form of quotas (e.g., southern states) may be low as the potential of increased enrolment have already been exhausted. States with shorter history of reservation or those where such a quota system has not been as systematic (north-central states) may observe a higher impact than in those states where systematic affirmative action has had a long history. Finally, states with no history of reservation (east and north-eastern states) are likely to experience the highest impact. Thus, the second hypothesis could be:

Hypothesis 2: The impact of affirmative action for OBC population in terms of higher increase (or lower decline) in enrolment in HEIs among the eligible population would be the highest in states with no history of affirmative action and the least in states with a long history of affirmative action. The impact in states with limited reservation history is likely to be somewhere in between.

While hypothesis 2 makes intuitive sense, a variable that can influence the relationship is the supply of HEIs in various states, even when we recognize inter-state migration for education. Affirmative action may increase overall demand for HEIs, resulting in the increase in the number of HEIs, both in the private and the public sector. States with a history of affirmative action may have seen such a supply response in the earlier period. However, states with no history of reservations in higher education may not have adequate supply of HEIs to absorb increased enrolment needs. Consequently, one needs to control for the supply of HEIs while estimating the impact. 
The next section discusses the data, and the empirical strategy applied throughout the paper to address the existing gap in literature.

\section{Data and Empirical Strategy}

\subsection{Data:}

We use the Unemployment and employment round of the NSS Data, which is a nationally representative household level sample survey collected by the National Sample Survey Organization of the Government of India. This quinquennial cross section household survey collects details of all individuals in a selected household, including information on their employment, education, rural land ownership, household expenditures and such. We primarily use the data from $68^{\text {th }}$ round, collected in the year 2011-12, as that is the only employment unemployment round that is available after the implementation rolled out throughout the country. However, for the tests of assumptions of the model, we also use the other three rounds of this data, collected in 1999-00, 2004-05, 2009-10. NSS is not a panel data. So households are different for each year. The first three rounds are part of major quinquennial survey, and the last one was almost same type of survey, apart from the fact that the sample size was marginally smaller. Since, the 2009-10 data almost coincides with the implementation of the legislation ${ }^{9}$, we do not expect any impact so soon. Then, the immediate next round of data and the most recent nationally representative data of same nature available is the 2011-12 data, which is primarily used in this study.

\footnotetext{
${ }^{9}$ Keeping in mind that implementation of the Act was not expected to be immediate, as due to issues with existing capacity, or nature of academic session, it took at least a year for the institutions to start phasing in the implementation.
} 
The data on district level educational infrastructure are collected from the online list of Ministry of Human Resource Development that covers all higher education institutions across the country. This online data base helps us to generate the district level statistics of number of educational institutions (both public and private) to capture the district-wise and state-wise statistics measuring number of HEIs, and their growth during the period of our interest. However, we do not have data on the actual capacity of each of these institutions. Consequently in our estimation, we only include them as covariates in the model. Nonetheless, it is important to recognize that the data has been painstakingly collected manually, cleaned/ and merged with NSS data to provide a reasonable control measure to capture the expansion of supply of HEIs across regions.

It would have been useful to separate the nature of supply response. Increase in public sector HEIs may have a higher impact on OBCs as reservation is in these institutions but there can be spillovers to other institutions if the supply is not adequate for the eligible population. Private sector HEIs can enhance participation of 'general' category more but the seats in public sector HEIs for them are frozen and new public sector institutions can enhance opportunities for them too. It may therefore be difficult to interpret the public-private division of HEIs.

\subsection{Identification Strategy}

The affirmative action policies in India are caste-based, and the country identifies a total of four major caste categories for the purpose of social sector policies. The SCs and the STs among them have been the most disadvantaged and have had the benefit of such positive discrimination policies for a long time. The OBCs are the most recent inclusion. The remaining category, known as 'general', remains outside the purview of such policy. 
As discussed earlier, the practice of reservations of seats in educational institutions for OBCs have been in place in four southern states in India, long before the implementation of the Central Act in 2008-09. These four southern states became 'experimental states,' long before the federal act on reservation came into being. Since education is also a state subject in India, southern states used that opportunity to advance the affirmative action in state funded institutions of higher education much before this central legislation. Due to long history of quotas in these, there has been high demand for higher education institutions, from a section of society not covered by the quota. Therefore, proactive southern states had simultaneous expansion of higher education institutions, with a higher share of private institutions ${ }^{10}$.

However, eastern states and all north-eastern states, as listed earlier, did not do much towards affirmative action for the OBCs in higher education and could be designated as 'nonexperimental' states till the 2008 Act $^{11}$. Broadly then, we identify four groups of states from our sample with different expected program effects. In the first group, we have four southern states with a long and systematic history of implementation of affirmative action and being in experimental category before other states. So, in 2004-05 data these states constitute the experimental category that turned non-experimental in 2008-09. Second group consists of the eight north-central states mentioned earlier with some history of affirmative action policies, but less systematic than the southern states. These states too remained in experimental category in the year 2004-05 and turned non-experimental in 2008-09. In the third and fourth groups, we have three eastern states, and six north-eastern states respectively, all of which remained in non-

\footnotetext{
${ }^{10}$ See summary statistics in Appendix table A1.

${ }^{11}$ Although the north-eastern states were similar to eastern states in terms lack of positive discrimination initiatives for OBCs; but the socio-economic conditions of STs and OBCs were better in the former groups of states than the latter. Share of ST population is higher in north-eastern (NE) states, but share of OBCs are closely same in both.
} 
experimental category till the year 2008-09 due to initiatives of lesser strengths ${ }^{12}$. However, there is a category reversal happening from the year 2008-09, as the last two groups turn experimental due to the introduction of central legislation; whereas, the erstwhile experimental states are not expected to have any significant change happening due to the Act.

For the identification of the impact of the Act on HE enrollment, we use the DD estimation strategy and conduct the analysis separately for the four state groups. In a cross-section of data, taken from the year 2011-12, the 'treated cohort' is the group of people aged 18 to 23 years. The 'controlled cohort' is the group of people aged 24 to 29 years, because the Act is expected to make a negligible difference in the $\mathrm{HE}$ participation to the latter. Therefore, in our DD estimation of Intent-to-treat effects, the first difference compares HE enrolment outcomes of OBCs aged 18-23 years ('treated') to OBC aged 24-29 years ('controlled'), in the year 2011-12. For the age group 24-29 years we have included who are currently studying (enrolled) as well as those who have completed HE. This is done because most of the persons in this age group would have enrolled before the implementation of the Act and would have completed HE by 2011-12. Currently enrolled persons in this age group would typically be those who are undergoing postgraduate education. Admittedly, a small proportion of the enrolled persons in this age group could have benefited by the Act; these would be those who benefited from affirmative action for their enrolment in post-graduate courses. Since the difference could be confounded by other factors affecting these two cohorts differently, we use the general population of the same age cohort as control group in our second level of difference, because they would have gone through the same changes that took place during this time, but were not eligible for quotas.

\footnotetext{
${ }^{12}$ Few fragmented initiatives of affirmative actions through quota at state government-aided institutions in the state of West Bengal, Orissa, which started much later in 1990s.
} 


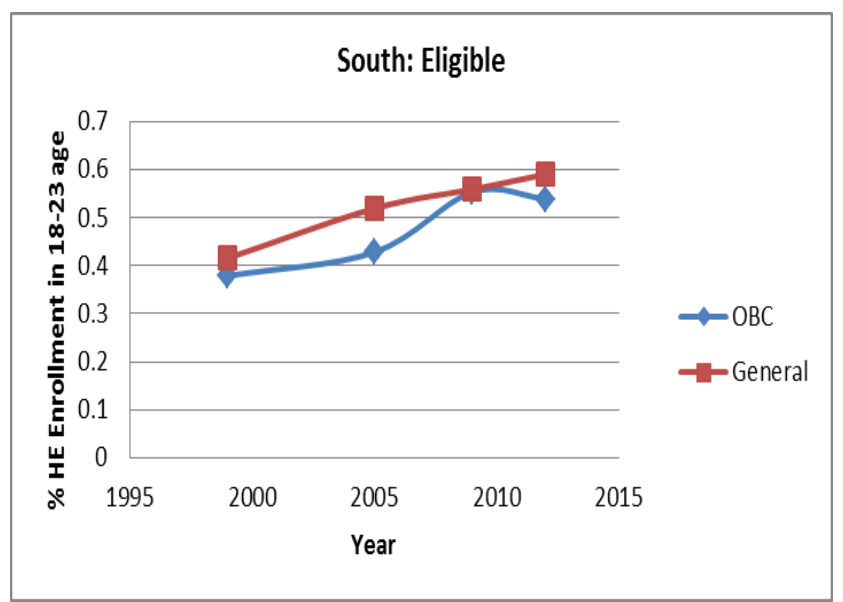

Figure 1

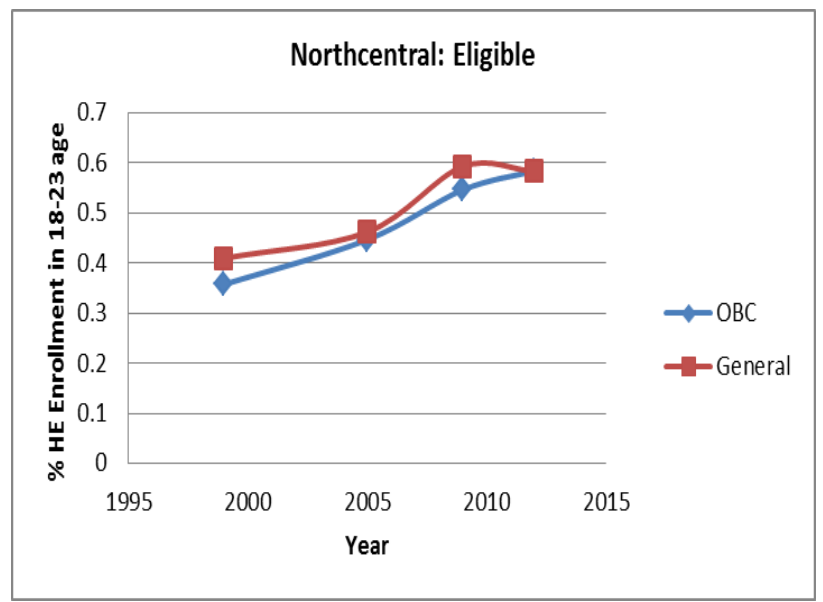

Figure 3

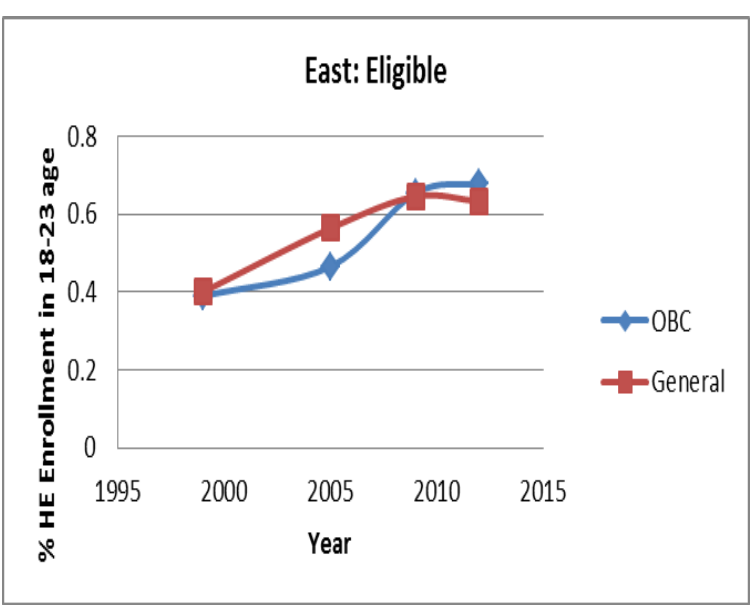

Figure 2

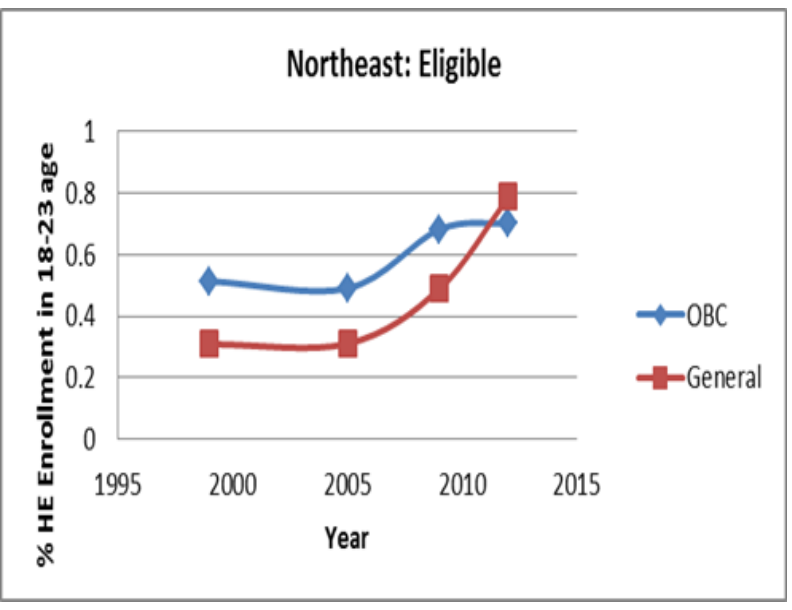

Figure 4

However, when we plot the current enrollment estimates of eligible population of the 18-23 years cohort separately for each of the state groups defined earlier, figures 1-4 indicate that the differential enrollment rates of OBCs over the years, have been different across regions. 
Table 1: Testing of Parallel Trends Assumption for full sample of all regions: Dependent variable is HE Enrollment- 18-23 yr as treated

\begin{tabular}{ll}
\hline & All India \\
\hline OBC & $-0.011^{*}$ \\
Treat & $0.371^{* * *}$ \\
& \\
OBC\#Treat & $-0.034^{* *}$ \\
2004 & $0.023^{* * *}$ \\
2009 & $0.035^{* * *}$ \\
& \\
OBC\#2004 & -0.002 \\
OBC\#2009 & -0.004 \\
Treat\#2004 & $0.061^{* * *}$ \\
Treat\#2009 & $0.155^{* * *}$ \\
& \\
OBC\#Treat\#2004 & -0.015 \\
OBC\#Treat\#2009 & 0.009 \\
$R^{2}$ & \\
$N$ & 0.25 \\
\hline
\end{tabular}

Note: Full sample includes 33 states, after merging Chhattisgarh with the parent state Madhya Pradesh, and Jharkhand with the parent state Bihar. * $p<0.1 ; * * p<0.05 ; * * *<<0.01$

We test for parallel trends in $\mathrm{OBC}$ and general enrolment growth in two periods prior to the program (1999-00, 2004-05) and one coinciding with the program (2009-10) in a separate univariate analysis, assuming the one coinciding with program implementation will not see a major change in enrollment. From Table 1, and Panel A of Table 2, we cannot reject the null hypothesis of coefficients of double interaction terms being same over the years for all India sample or for separate state groups respectively. The only exception is the north-central group of states, where the double interaction term is statistically significant at ten percent level, for the year 2004-05. 
Table 2: Testing of Parallel Trends Assumption for DD estimation by State groups: Dependent variable is HE participation dummy of 18-29 years

Panel A: OBC dummy interacted with years

\begin{tabular}{lllll}
\hline & South & East & Northcentral & Northeast \\
\hline OBC & -0.001 & -0.013 & $-0.04^{* *}$ & 0.046 \\
Yr:2004 & $0.074^{* * *}$ & $0.102^{* * *}$ & $0.039^{* * *}$ & 0.002 \\
Yr:2009 & $0.113^{* * *}$ & $0.152^{* * *}$ & $0.121^{* * *}$ & 0.109 \\
& & & & \\
OBC\#2004 & -0.034 & -0.058 & $0.037^{*}$ & 0.051 \\
OBC\#2009 & 0.005 & 0.043 & 0.045 & 0.032 \\
$R^{2}$ & & & & \\
$N$ & 0.01 & 0.02 & 0.01 & 0.02 \\
& 16,619 & 7,265 & 33,213 & 2,670 \\
\hline
\end{tabular}

Panel B: Treated (18-23 years) and OBC dummy interacted with years

\begin{tabular}{|c|c|c|c|c|}
\hline $\mathrm{OBC}$ & 0.007 & -0.015 & -0.02 & $-0.096 * * *$ \\
\hline treat & $0.391 * * *$ & $0.350 * * *$ & $0.364 * * *$ & $0.191 *$ \\
\hline OBC\#treat & -0.04 & 0.004 & -0.033 & $0.301 * *$ \\
\hline Yr:2004 & 0.019 & 0.029 & $0.024 * *$ & -0.011 \\
\hline Yr:2009 & $0.044 * * *$ & -0.01 & $0.025 *$ & $-0.079 * * *$ \\
\hline OBC\#2004 & 0.005 & -0.042 & -0.002 & $0.106 * * *$ \\
\hline OBC\#2009 & -0.016 & 0.004 & 0.011 & $0.135 * * *$ \\
\hline treat\#2004 & $0.084 * *$ & $0.134 * * *$ & 0.028 & 0.012 \\
\hline treat $\# 2009$ & $0.099 * *$ & $0.254 * * *$ & $0.158 * * *$ & $0.258 * *$ \\
\hline OBC\#treat\#2004 & -0.059 & -0.046 & 0.039 & -0.131 \\
\hline OBC\#treat\#2009 & 0.048 & 0.016 & -0.005 & -0.146 \\
\hline$R^{2}$ & 0.24 & 0.30 & 0.24 & 0.24 \\
\hline$N$ & 16,619 & 7,265 & 33,213 & 2,670 \\
\hline
\end{tabular}

Note: The sample includes a total of 21 states, which could reasonably be divided across four regions for the purpose of the study. $* p<0.1 ; * * p<0.05 ; * * * p<0.01$

This indicates that our DD estimation would provide valid and consistent estimates if we could also control for time-varying treatment specific effects that are not due to the Act. However, the only data point that we have post-implementation is from the year 2011-12, which does not allow 
us to control for the above fact. This leads us to use the 18-23 years cohort as the 'treated' in the first difference.

Panel B of Table 2 shows that we cannot reject the null hypothesis of coefficients of double interaction terms being same over years, as the triple interaction terms including the years prior to the act are not statistically significant for any region. This indicates that the DD estimation will provide estimates for valid treatment effects if we use 18-23 years cohort as treated as against 24-29 years cohort as control group.

Also, the differential enrollment between $\mathrm{OBCs}$ and general population over years vary widely across the regions. OBCs have been consistently doing better than the general population in Northeast region, and that too without a long history of affirmative action policies. This differential enrolment patterns in the Northeast indicates the South and East regions can further be used for more precise estimates of the treatment effects.

Table 3: Percentage of OBCs Out of Total Population in Each State Group, Across Years

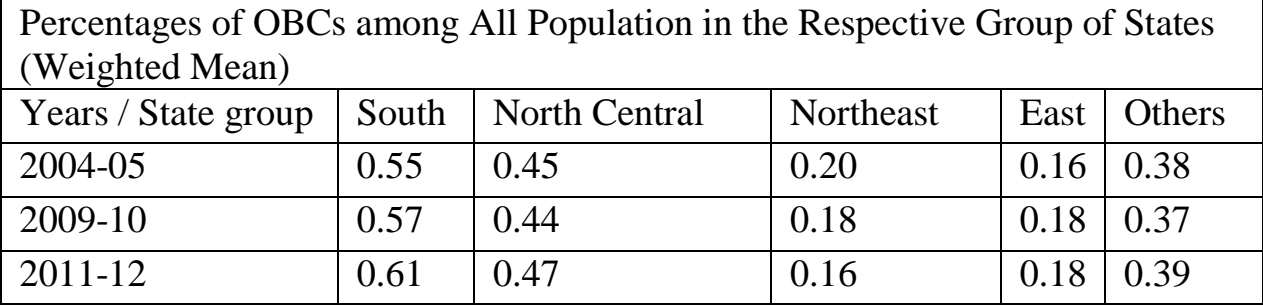

Note: All India sample of 33 states. The percentage distribution is closely the same when we look at distribution among 18-25 years old.

Table 3 also indicates that share of OBCs among all other castes are similar in South and East regions. In the post Act period, Eastern states are the new experimental states as compared to 
Southern states. Therefore, in the next stage we conduct a triple difference estimate, by comparing the double difference computed above in the Eastern (experimental) states, with the same double difference in Southern group of (non-experimental) states. The latter group serves as a counterfactual for historical reasons explained earlier, and also because the trends in enrollment for OBCs and general have been same in these regions. We test the parallel trend assumption in period 1999, 2004, and 2009 and find that we do not reject the null hypothesis of parallel trends with the coefficients on the triple and quadruple interaction terms not being statistically significant (in columns 1 and 2, Table 4).

Table 4: Testing of Parallel Trends Assumption in DDD: Sample of South and East

\begin{tabular}{lll}
\hline & $\begin{array}{l}\text { Triple interaction including } \\
\text { year }\end{array}$ & $\begin{array}{l}\text { Quadruple interaction } \\
\text { including year }\end{array}$ \\
\hline OBC & 0 & 0.014 \\
East & 0.001 & $0.024^{*}$ \\
OBC\#East & -0.002 & -0.005 \\
Yr:2004 & $0.071^{* * *}$ & 0.014 \\
Yr:2009 & $0.111^{* * *}$ & $0.042^{* * *}$ \\
OBC\#2004 & -0.035 & \\
OBC\#2009 & 0.008 & 0.002 \\
East\#2004 & 0.030 & -0.010 \\
East\#2009 & 0.049 & 0.010 \\
& & -0.033 \\
OBC\#East\#2004 & -0.038 & $-0.075^{*}$ \\
OBC\#East\#2009 & 0.014 & -0.032 \\
Treat & & $0.371^{* * *}$ \\
OBC\#treat & & $-0.051^{*}$ \\
East\#treat & & -0.040 \\
OBC\#East\#treat & & 0.031 \\
2004\#treat & & $0.089^{* *}$ \\
2009\#treat & & $0.101^{* *}$ \\
OBC\#2004\#treat & & -0.056 \\
OBC\#2009\#treat & & 0.041 \\
East\#2004\#treat & & 0.050 \\
East\#2009\#treat & & $0.135^{* *}$ \\
& &
\end{tabular}


OBC\#East\#2004\#treat

OBC\#east\#2009\#treat

$R^{2} \quad 0.01$

Note: Sample of seven states. $* p<0.1 ; * * p<0.05 ; * * * p<0.01$
0.042

0.021

0.23

23,857

However, comparing the $\mathrm{OBC}$ from different states may also include the impact of timeinvariant state specific effects that may have benefited OBC from the two groups of states differently, which would bias our estimation results. For example, if southern states already had higher educational participation on average than eastern states, then the impact of the Act would be underestimated. We address this problem by including state-specific variables, such as state level growth in number of HE institutions, both private and government. The estimate will also include the year-specific effect which is correlated with but not due to the Act, such as, if the participation has increased over years. So, our 'Act' variable will pick up all year-specific, statespecific effects including the effects of Act. Therefore, we need to include a control group from both groups of states for whom the Act should make no difference. The 'general' being the closest to the OBCs amongst caste groups in terms of socio-economics conditions, and both remaining outside the positive discrimination policy in higher education till the 2008 Act, we use 'general' as a comparison group. Therefore, we compare a 'second level treatment' group (OBC) and 'second level control' group (general population) among 'treated' and 'controlled' age cohorts, in each group of states for whom the Act made no difference, as against each group for whom the Act mattered. The inclusion of treatment group dummy variable helps us to control for treatment specific time-invariant national level differences, which leads us to estimate the difference-in-difference-in difference model. 
Panels A and B of appendix table A1 provide basic statistics for caste groups and regions. Interestingly, the sample characteristics do not seem to be different across caste groups and regions. The only significant difference seems to be that the proportion of heads of households having higher secondary or graduate education is lower in OBC households as compared to 'general' households.

We expect the triple difference estimate of the following model to produce an unbiased estimate of the Act on HE enrollment of OBCs when the analysis is restricted two regions - the South and the East, otherwise similar in educational achievements of both the groups:

$$
\begin{aligned}
& Y_{\text {ihds }}=\beta_{0}+\beta_{1} . O_{\text {ihds }} * T_{i h d s} * E_{i h d s}+\beta_{2 .} . O_{i h d s} * E_{i h d s}+\beta_{3 .} T_{i h d s} * E_{i h d s}+\beta_{4 .} O_{i h d s} * T_{i h d s}+\beta_{5 .} O_{i h d s}+\beta_{6 .} T_{i h d s} \\
& +\beta_{7 .} E_{i h d s}+\gamma_{1} . X_{i h d s}+u_{i h d s}
\end{aligned}
$$

Where $Y_{i h d s}$ is the indicator for current HE enrolment of 18-29 years old (=1) of an individual $i$, in household $h$, in district $d$, and in state $s . T_{i n d s}$ is the indicator for the person being treated (of age group 18-23, as against control being in age group 24-29), $O_{i h d s}$ is the indicator for individual belonging to the social group, OBC. $E_{\text {inds }}$ takes a value of 1 if the individual belongs to the state group East (else, it takes a value zero for individual from South). $X_{\text {ihds }}$ is the vector of individual, household level, district and state level covariates ${ }^{13}$, as explained below. We estimate the model for the year 2011-12 data for the sample of 18-29 years cohort in the state groups of South and East regions.

\footnotetext{
${ }^{13}$ In different specifications, not shown in the text, we control for district level school infrastructure as available from the DISE (District Information System in Education) data of the Government of India, instead of state level infrastructure of higher education. Our findings remain same even with that specification.
} 
If 'program' effect is heterogeneous among individuals then pre-treatment differences in observed characteristics can generate difference in outcomes (Abadie, 2005). Hence, we control for individual and household level factors, which could be causally linked to the difference in participation between the 'treated' and the 'control' groups. As individual level controls, we use age, quadratic form of age, and sex dummies. To control for the changes in standards of living, we use few categories of average household expenditures as covariates, categories being created on the basis of poverty lines ${ }^{14}$. We control for the dependency ratio in the household, defined by the ratio of total number of people below 18 years and above 60 years, to the total household size. As parent's education is found to be highly correlated to children's participation in HE (Basant and Sen 2014b), we use the educational level of household head as a proxy for parental education, as the latter is not reported in the data.

Since the central legislation was implemented only in the year 2008-09, and the latest available nationally representative sample survey data that we have is of the year $2011-12^{15}$, we focus on the current enrolment figures in higher education to measure participation for the 18-23 age cohort, instead of using completion rate ${ }^{16}$. As mentioned, we use enrollment plus the completion rate for the older age cohort (24-29). To check the robustness of our estimates, we have estimated our model by using only enrollment rates for the older age cohort as well ${ }^{17}$. We restrict

\footnotetext{
${ }^{14}$ The poverty lines estimates are taken from the documents of the erstwhile Planning Commission, Government of India, for the respective years.

${ }^{15}$ Considering the fact that the data collected at 2009-10, almost coincided with when the implementation just started in few institutions.

${ }^{16}$ See the stock versus flow analysis of Basant and Sen (2010) for further details on difference in these measurements.

${ }^{17}$ All our estimation results are very similar if we include only the current enrollment figures of the controlled (2429 years) cohort, instead of both completion and enrollment together.
} 
the analysis among population, who has already crossed the threshold of school education to become eligible for higher education, for two reasons: One, this way, we minimize the difference in unobservables between $\mathrm{OBCs}$ and general population that would influence their decision to participate in HE differently making our estimates biased and inconsistent. Second, the immediate impact of policy can only be seen among population who are eligible for HE participation.

\section{Results}

\subsection{Discussion of results}

The DD estimates of the country level sample ${ }^{18}$ are presented in table 5. The first columns represent estimates of naïve models, without any covariates. In the second, third and fourth columns, we have added individual, household, and state level covariates respectively. So, the last column reports results of full sample estimates for each region.

\footnotetext{
${ }^{18}$ This is done with the all India sample of 33 states, where the states of Chhattisgarh and Jharkhand have been merged with their parent states Madhya Pradesh and Bihar respectively.
} 
Table 5: DD estimation of All India Sample: Dependent variable is HE Enrollment

\begin{tabular}{|c|c|c|c|c|}
\hline & No Controls & $\begin{array}{l}\text { +Individual } \\
\text { controls }\end{array}$ & $\begin{array}{l}\text { +Household } \\
\text { controls }\end{array}$ & + State controls \\
\hline $\mathrm{OBC}$ & -0.003 & -0.008 & 0.01 & $0.021 * *$ \\
\hline Treat & $0.535 * * *$ & $0.203 * * *$ & $0.198 * * *$ & $0.195 * * *$ \\
\hline OBC\#Treat & $-0.03 *$ & $-0.04 * *$ & $-0.039 * *$ & $-0.041 * *$ \\
\hline male & & $0.055 * * *$ & $0.058 * * *$ & $0.058 * * *$ \\
\hline hh_mem_age & & $-0.305^{* * *}$ & $-0.316^{* * *}$ & $-0.325 * * *$ \\
\hline agesq & & $0.005^{* * *}$ & $0.005^{* * *}$ & $0.006^{* * *}$ \\
\hline dep_ratio & & & -0.03 & -0.045 \\
\hline verypoor & & & $-0.194 * * *$ & $-0.212 * * *$ \\
\hline vulnble & & & $-0.043^{* *}$ & $-0.059 * * *$ \\
\hline midclass & & & $-0.019 *$ & $-0.024 * *$ \\
\hline sec_orbelow_hd & & & $0.044 * * *$ & $0.039 * * *$ \\
\hline hisec_hd & & & $0.037 *$ & $0.032 *$ \\
\hline grad_hd & & & $0.111 * * *$ & $0.104 * * *$ \\
\hline fem_head & & & 0.005 & 0.002 \\
\hline rural & & & 0.002 & -0.008 \\
\hline increase_state_govt_he 0411 & & & & 0 \\
\hline increase_state_pvt_he 0411 & & & & 0 \\
\hline$R^{2}$ & 0.28 & 0.34 & 0.35 & 0.35 \\
\hline$N$ & 27241 & 27241 & 27241 & 27241 \\
\hline
\end{tabular}

Note: All India sample of 33 states. $* p<0.1 ; * * p<0.05 ; * * * p<0.01$

The full model with individual, household, and state fixed effects as produced in the last column indicates that eligible $\mathrm{OBCs}$ seem to have a 0.02 point higher chance of participation than general population of 18-29 age group in the year 2011-12. 'Treated' cohort of 18-23 years seems to have 0.13 point higher chance of participation than the 'controlled' cohort of 24-29 years. However, the treatment effect, as indicated by the negative sign of the triple interaction term implies that the difference between treated (18-23 years) cohort and control (24-29 years) are 0.04 points lower for $\mathrm{OBC}$ than general after the implementation of the act. The eligible OBCs of relevant age seem to participate less in HE than general population, even with complete roll-out of affirmative action which rejects the first hypothesis. 
Table 6: DD estimation for the year 2011-12: Dependent variable is HE Participation

\begin{tabular}{|c|c|c|c|c|}
\hline Panel A: South & No Control & $\begin{array}{l}\text { + Individual } \\
\text { controls }\end{array}$ & $\begin{array}{l}\text { + Household } \\
\text { controls }\end{array}$ & $\begin{array}{l}+ \text { State } \\
\text { controls }\end{array}$ \\
\hline$\overline{\mathrm{OBC}}$ & -0.002 & -0.005 & 0.003 & -0.004 \\
\hline treat & $0.532 * * *$ & $0.128 * * *$ & $0.114^{* * *} *$ & $0.115^{* * *}$ \\
\hline OBC\#treat & -0.049 & -0.045 & -0.033 & -0.02 \\
\hline$R^{2}$ & 0.26 & 0.35 & 0.37 & 0.37 \\
\hline$N$ & 6,495 & 6,495 & 6,495 & 6,495 \\
\hline Panel B: East & No Control & $\begin{array}{l}\text { + Individual } \\
\text { controls }\end{array}$ & $\begin{array}{l}+ \text { Household } \\
\text { controls }\end{array}$ & $\begin{array}{l}+ \text { State } \\
\text { controls }\end{array}$ \\
\hline$\overline{\mathrm{OBC}}$ & -0.009 & -0.015 & 0.004 & 0.022 \\
\hline treat & $0.578 * * *$ & $0.236 * * *$ & $0.215^{* * * *}$ & $0.208 * * *$ \\
\hline OBC\#treat & 0.055 & 0.019 & 0.020 & 0.021 \\
\hline$R^{2}$ & 0.37 & 0.43 & 0.45 & 0.45 \\
\hline$N$ & 2,635 & 2,635 & 2,635 & 2,635 \\
\hline Panel C: Northcentral & No Control & $\begin{array}{l}\text { + Individual } \\
\text { controls }\end{array}$ & $\begin{array}{l}\text { + Household } \\
\text { controls }\end{array}$ & $\begin{array}{l}+ \text { State } \\
\text { controls }\end{array}$ \\
\hline OBC & 0.019 & 0.013 & $0.036^{* *}$ & $0.037 * *$ \\
\hline treat & $0.515 * * *$ & $0.212 * * *$ & $0.210^{* * *}$ & $0.207 * * *$ \\
\hline OBC\#treat & -0.018 & -0.022 & -0.026 & -0.027 \\
\hline$R^{2}$ & 0.27 & 0.32 & 0.33 & 0.33 \\
\hline$N$ & 12,932 & 12,932 & 12,932 & 12,932 \\
\hline Panel D: Northeast & No Control & $\begin{array}{l}\text { + Individual } \\
\text { controls }\end{array}$ & $\begin{array}{l}+ \text { Household } \\
\text { controls }\end{array}$ & $\begin{array}{l}+ \text { State } \\
\text { controls }\end{array}$ \\
\hline$\overline{\mathrm{OBC}}$ & $-0.062 *$ & $-0.057 * *$ & -0.052 & $-0.070^{*}$ \\
\hline treat & $0.676^{* * *}$ & $0.294 * *$ & $0.294 * *$ & $0.291 * *$ \\
\hline OBC\#treat & -0.021 & -0.052 & -0.039 & -0.037 \\
\hline$R^{2}$ & 0.45 & 0.52 & 0.54 & 0.54 \\
\hline$N$ & 943 & 943 & 943 & 943 \\
\hline
\end{tabular}

$* p<0.1 ; * * p<0.05 ; * * * p<0.01$

The DD estimation results for four regions are presented in Table 6. The treated cohort has 0.12 to .29 (Panel A - D) point higher chances of participation than controlled cohort among both the groups in all regions.

However, the double interaction term in the full model is not statistically significant in any region, resulting in failure to accept the first hypothesis. The treated cohort among OBCs may 
not have been able to reap the benefit of the Act after the implementation to make a differential growth of participation as compared to the general population. The signs are negative in all regions, except for the East, which indicates that the treated cohort among OBCs in the eastern region only might have been slightly benefitted from the Act.

The result from the East region strengthens the importance of our second hypothesis further, where we conduct a triple difference strategy to compare the outcome in East (experimental region) vis-à-vis the South (non-experimental region).

It is important to note here, that the OBCs of Northcentral region seem to have 0.04 point higher participation than general population (Panel $\mathrm{C}$ of Table 6), which cannot be attributed to the Act. This finding seems noteworthy in the context that the Northcentral region is the power lobby of India politics with a strong interest in affirmative action for $\mathrm{OBCs}$, and which has seen several incidents of violent protests in recent times.

Other covariates have signs as expected in all the regions other than the Northeast. Being a male or being younger in age increases the chances of participation in other three regions. The positive and statistically significant estimates of the quadratic form of age indicate convexity in the relationship. Households have lower chances of children's HE enrolment if they are poor, or their heads have lower levels of education in general. ${ }^{19}$ The demography of the northeastern region being very different, comprising of a very low share of general population, the gender inequality is less. Household head's education seem to have a negative relationship in the Northeast regions at the lower levels of education, which indicates that that certain unobservable

\footnotetext{
${ }^{19}$ Full sample estimation results is presented in appendix table A2
} 
characteristics of that region might be correlated to the head's education and making that estimate biased. Northeast has more supply side constraints in education infrastructure at all levels, which might have affected the head's education, and children's educational participation. Increase in number of government and private higher education institutions at the state does not seem to have a strong effect in our model, which may be due to the fact that we only have the number of institutions and are not able to capture actual capacity. However, dropping them from the regression changes the coefficients slightly in few specifications.

Table 7: DDD estimation: South Compared to East

\begin{tabular}{|c|c|c|c|c|}
\hline & $\begin{array}{l}\text { No } \\
\text { Covariates }\end{array}$ & $\begin{array}{l}\text { Add Individual } \\
\text { covariates }\end{array}$ & $\begin{array}{l}\text { Add Household } \\
\text { covariates }\end{array}$ & $\begin{array}{l}\text { Add State } \\
\text { covariates }\end{array}$ \\
\hline $\mathrm{OBC}$ & -0.002 & -0.004 & 0.002 & -0.005 \\
\hline treat & $0.532 * * *$ & $0.131 * * *$ & $0.115 * * *$ & $0.114 * * *$ \\
\hline OBC\#treat & -0.049 & -0.045 & -0.034 & -0.031 \\
\hline East & -0.004 & -0.005 & 0.004 & 0.017 \\
\hline OBC\#East & -0.007 & -0.013 & -0.002 & 0.003 \\
\hline treat\#East & 0.046 & $0.091 * *$ & $0.099 * * *$ & $0.102 * * *$ \\
\hline OBC\#treat\#East & $0.104 *$ & 0.064 & 0.054 & 0.052 \\
\hline Male & & $0.056^{* * *}$ & $0.055 * * *$ & $0.055^{* * *}$ \\
\hline Age & & $-0.392 * * *$ & $-0.422 * * *$ & $-0.419 * * *$ \\
\hline Age square & & $0.007 * * *$ & $0.008 * * *$ & $0.007 * * *$ \\
\hline Dependent Ratio & & & $-0.078 * *$ & $-0.077 *$ \\
\hline Very poor & & & -0.067 & -0.048 \\
\hline Vulnerable & & & $-0.105 * * *$ & $-0.102 * * *$ \\
\hline Middle class & & & $-0.058 * * *$ & $-0.058 * * *$ \\
\hline Secor below head & & & $0.041^{*}$ & $0.045^{*}$ \\
\hline HS head & & & $0.046^{*}$ & $0.051 *$ \\
\hline Grad head & & & $0.1 * * *$ & $0.103 * * *$ \\
\hline Female head & & & & 0.005 \\
\hline Rural & & & & 0.009 \\
\hline Increase of state_govt_he 0411 & & & & $0.0 *$ \\
\hline Increase of state_pvt_he0411 & & & & 0.00 \\
\hline$R^{2}$ & 0.28 & 0.37 & 0.38 & 0.39 \\
\hline$N$ & 9,130 & 9,130 & 9,130 & 9,130 \\
\hline
\end{tabular}

Note: Sample of seven states. ${ }^{*} p<0.1 ; * * p<0.05 ; * * * p<0.01$ 
The triple difference estimates of the sample for the South and Eastern regions are presented in table 7. The OBCs do not seem to be very different from general population in HE participation in these regions, although the sign of the coefficient in full sample is negative, but value is as small as 0.005 . The treated cohort seems to enroll more in HE, in all specifications, with a lower bound of 0.11 .

The estimates for the triple interaction terms are positive and lose statistical significance once we include all covariates in the full model. This indicates that experimental Eastern states may have been benefited by the Act, as compared to non-experimental southern states. However, the high standard errors for the triple interaction term limit our conclusion.

For further explanation of the results, the first difference can be seen as the difference in enrollment between the treated cohort and controlled cohort. The second difference is the difference of above difference between the OBCs and the general, which seems to be negative (although not statistically significant). This indicates that younger cohort of OBCs seem to be participating less than the younger cohort of general population. So, the triple difference estimates measure the extent to which eastern (experimental) states performed better than the southern (non-experimental) states in bridging the caste gap between cohorts. If the affirmative action works as expected, then the signs of the triple interaction terms should be positive. Although, our results from the triple difference estimation is positive, but are not statistically significant when we control for individual, household and state fixed effects. Estimates for all other covariates of the model have signs as expected. 
The findings from both the double difference estimation done at regional levels, and triple difference estimation for two seemingly comparable regions point out that while the difference in HE participation between OBCs and general is not very significant to begin with, the desired outcomes of affirmative action is still inconclusive, and causal impact is not in the expected direction. The all India sample, which includes 12 more states than our regional level analyses, also indicates negative treatment effects.

\subsection{Supply side expansion}

These findings lead us to explore if the supply side capacity expansion in India could be correlated with higher HE participation simultaneously. For this purpose, we collate the data on HE institutions in India, from the online sources of Ministry of Human Resources of the Government of India. The data indicates a steep expansion of HE institutions in southern states between the year 2004-05 to 2009-10 (about 855 institutions per year), followed by a much slower growth (223 institutions per year) in the second period. This is shown in table 8 and figure 2a-figure $2 \mathrm{~b}$, and corresponds positively to the rate of $\mathrm{OBC}$ participation in southern states between these two periods. In Eastern region too, the rate of expansion in first period has been larger than second period, although not as large a difference as in southern states (a yearly growth of 47 institutions in first period as against 16 institutions in second period). The growth in $\mathrm{OBC}$ participation in these states follows that pattern as well; that is, increase in participation in first period followed by a drop in second period. Without having the data on capacity of these institutions, it is not possible to draw any conclusion on the simultaneous impact of the supply side expansion. However, our estimates should not be affected by the capacity expansion as that would generate similar opportunities for the $\mathrm{OBCs}$ and general population. The government institutions had to expand their capacities for accommodating the designated 'quota' of OBCs, 
without compromising the space for general population. Private institutions do not fall under this legislation.

In Northeast region, there has been marginal expansion in number of HE institutions between two periods (growth of 5 institutions per year in first period as against 3.5 institutions per year in second period). This does not correspond to the continuous increase in OBC participation in both the periods, and again, we cannot causally link the change in participation to capacity expansion because we do not have information on capacity of each of them.

\section{Conclusion}

There has been a policy change to encourage participation in higher education among OBCs. The general trend of participation of $\mathrm{OBCs}$ indicates that participation has indeed increased over years, but whether that can be credited to the affirmative action policy or it is merely a representation of the overall trend cannot be established without testing for a causal relationship. OBC participation has increased post 2009 (table 8), but if the positive discrimination through quota is to be credited for that, then higher OBC participation should be reflected through: one, higher increase in age-relevant enrolment among OBCs as compared to groups which did not benefit from affirmative action; two, higher age-relevant enrollment of OBCs in states which newly introduced this policy; three, more enrollment in government institutions; and four, more enrollment in states that have experienced faster expansion of HE institutions.

Our estimation strategies are able to find a causal relationship through the first two channels. For all India sample, 18-29 years cohort of OBCs are doing better than the general population in HE participation in most recent data; 18-23 years cohort has higher chances of participation than 24- 
29 years cohort; but the positive difference in participation between younger 18-23 years cohort and older 24-29 years cohort among OBCs is less than the same among general population. This indicates that even after implementation of affirmative action, the enrollment rates in $\mathrm{HE}$ of eligible OBCs are still not 'increasing' faster than the enrollment rates of the eligible general population.

The expectation was that the Act would have higher impact in states which have no or very limited experience of affirmative action (experimental states) as compared to those having some history of affirmative action prior to the implementation of the Act (non-experimental states). As we compare the experimental states for which the policy is expected to have a stronger impact, with the other non-experimental states (with already existing policies), the intent-to-treatment effect seems to be positive but not statistically significant. Apparently, the Act has not had a significant positive impact on OBC participation in states which newly introduced this policy. This difference in findings between our double-difference and triple-difference estimation results raises concerns regarding the generalized nation-wide policy for issues which are more regional in nature.

An evaluation of the deficits in HE participation by different socio-religious groups has shown that if one focuses on the population in the relevant age group which is eligible to go to college, OBCs do not show any deficits; their share among the enrolled in fact is slightly higher than their share in the eligible population (Basant and Sen, 2010). In such a situation, the incremental impact of the 2008 Act may not be very significant as bulk of those among the eligible population who wanted to participate in HE are already doing so. The impact may become 
evident if $\mathrm{OBC}$ reservation incentivizes more and more persons in the social group to cross the school threshold. But, as has been argued by Basant and Sen (2014a) such an increase in demand may face supply constraints at the school level.

The supply side constraints may also be operational at the HE level. Consequently, one can argue that encouraging participation through capacity expansion of HE system is a better policy option to address such problems of lower participation. And this may be even more relevant as a complement to the policies of affirmative action. But, due to paucity of data that can capture capacity of HE institutions in India (public and private), we are unable to design a measure to estimate the causal impact of capacity expansion. Consequently, the last two channels remain unexplored but they remain important areas for future work.

However, as a note of caution, one should mention that the policy of OBC reservation is still quite recent and a decent amount of time may be required to assess its impact and reach an unequivocal verdict. In that context, our exercise can be seen as a first step of evaluating the policy and can be replicated after a lapse of few years, to ascertain if the same findings persist before articulating a clear policy recommendation. Also, in order to control for the fact that impact may not be immediate; one could use the lagged treatment variable analysis after few years, which cannot be done so soon. 


\section{$\underline{\text { References }}$}

Alona, Sigal and Ofer Malamudb. (2014). "The impact of Israel's class-based affirmative action policy on admission and academic outcomes," Economics of Education Review, 40, pp123-139.

Angrist, Joshua D. and Jorn-Steen Pischke. (2009). Mostly Harmless Econometrics. Princeton, NJ: Princeton University Press, p 79.

Azam, Mehtabul and Andreas Blom. (2008). "Progress in Participation in Tertiary Education in India from 1983 to 2004," Policy Research working paper 4793, Human Development Department, The World Bank, South Asia Region, December.

Bagde, Surendrakumar., Dennis Epple, and Lowell Taylor. (2016). "Does Affirmative Action Work? Caste, Gender, College Quality, and Academic Success in India, American Economic Review, forthcoming.

Baley, Susan. (1999). "Caste, Society and Politics in India from the Eighteenth Century to the Modern Age," The New Cambridge History of India, Volume IV, Cambridge: Cambridge University Press.

Basant, Rakesh and Gitanjali Sen. (2010). "Who Participates in Higher Education in India? Rethinking the Role of Affirmative Action," Economic and Political Weekly, Vol xlv (39), September.

Basant, Rakesh and Gitanjali Sen. (2014a). "Access to higher education in India: an exploration of its Antecedents," Economic and Political Weekly, December.

Basant, Rakesh and Gitanjali Sen. (2014b). "Parental Education as a Criterion for Affirmative Action." World Development, December.

Bertrand, Marianne. Rema Hanna, and Sendhil Mullainathan. (2010). "Affirmative action in education: Evidence from engineering college admissions in India," Journal of Public Economics, 94(1-2): 16-29.

Chan, Jimmy and Erik Eyster. (2003). "Does Banning Affirmative Action Lower College Student Quality?” American Economic Review, 93(3):858-873.

Cunningham, C. D. (2001). "Affirmative Action: Comparative Policies and Controversies," International Encyclopedia of the Social \& Behavioral Sciences, pp. 210-214

Deshpande, Ashwini. (2011). Grammar of Castes: Economic Discrimination in Contemporary India, Oxford University Press, India.

Galanter, Marc. (1984). Competing Equalities: Law and the Backward Classes in India, Berkeley: University of California Press; New Delhi: Oxford University Press.

Ghildiyal, Subodh. (2014). "UPA's poll sop: Cabinet okays inclusion of jats in OBC list," Times of India, March 3, available at: http://timesofindia.indiatimes.com/india/UPAs-poll-sopCabinet-okays-inclusion-of-jats-in-OBC-list/articleshow/31299546.cms, accessed on March 31, 2014.

Hinrichs, Peter. (2014). "Affirmative action bans and college graduation rates," Economics of Education Review, 42:43-52.

Holzer, Harry and David Neumark. (2000). "Assessing Affirmative Action," Journal of Economic Literature, Vol. XXXVIII, September, pp. 483-568.

Kaur, Harpreet and R. K. Suri. (2009). Reservation in India, Recent Perspective in Higher Education. 
Osborne, Evan. (2001). "Culture, Development, and Government: Reservations in India," Economic Development and Cultural Change, 49(3):659-685.

Parikh, Sunita. (2001). "Affirmative action, caste, and party politics in contemporary India," in Color lines: Affirmative action, immigration, and civil rights options for America, ed. John David Skrentny.

Rao, D. Narsimha. and M. Ramchander, (1982). " Reservations in Backward Classes: In Search of Criteria,' in Reservation Policy in India, ed. B. A. V Sharma and Madhusudhan Reddy, New Delhi: Light and Life.

Sodhi, Prerna. (2009). “OBC admissions better, but still on lower side," The Indian Express, July 4, accessed online at http://indianexpress.com/article/cities/delhi/obc-admissions-betterbut-still-on-lower-side/ .

Sowell, Thomas. (2004). Affirmative action around the world-An empirical study. Yale University Press.

Thorat, Sukhadeo, Nitin Tagade, Ajaya K Naik. (2016). "Prejudice against Reservation Policies How and Why?" Economic and Political Weekly, LI(8), February 20.

Zwart, Frank de. (2000). "The Logic of Affirmative Action: Caste, Class and Quotas in India," Acta Sociologica, 43(3): 235-249. Sage Publications, Ltd. 
Table 8: Growth of OBC Enrolment in HE and Growth of HE Institutions in 3 States Groups in last decade

\begin{tabular}{|l|l|l|l|l|l|l|l|}
\hline & \multicolumn{2}{|l|}{$\begin{array}{l}\text { \% Currently in HE: In 18- } \\
\text { 25 age group of OBC }\end{array}$} & \multicolumn{2}{l|}{$\begin{array}{l}\text { Average Yearly Change in } \\
\text { Participation }\end{array}$} & \multicolumn{2}{l|}{$\begin{array}{l}\text { Average Yearly growth in } \\
\text { number of HE institutions }\end{array}$} \\
\hline Year & $04-05$ & $09-10$ & $11-12$ & 1 st period* & 2nd period** & 1st period & 2nd period \\
\hline South & 0.36 & 0.47 & 0.45 & 0.02 & -0.01 & 855.2 & 223 \\
\hline Northeast & 0.43 & 0.55 & 0.59 & 0.03 & 0.02 & 5.2 & 3.5 \\
\hline East & 0.37 & 0.57 & 0.53 & 0.04 & -0.02 & 47.2 & 16 \\
\hline
\end{tabular}

*1st period refers to the period between 2004-05 to 2009-10, before the implementation of 2008 Act.

**2nd period refers to the period after implementation, that are, between years 2009-10 to 2011-12.

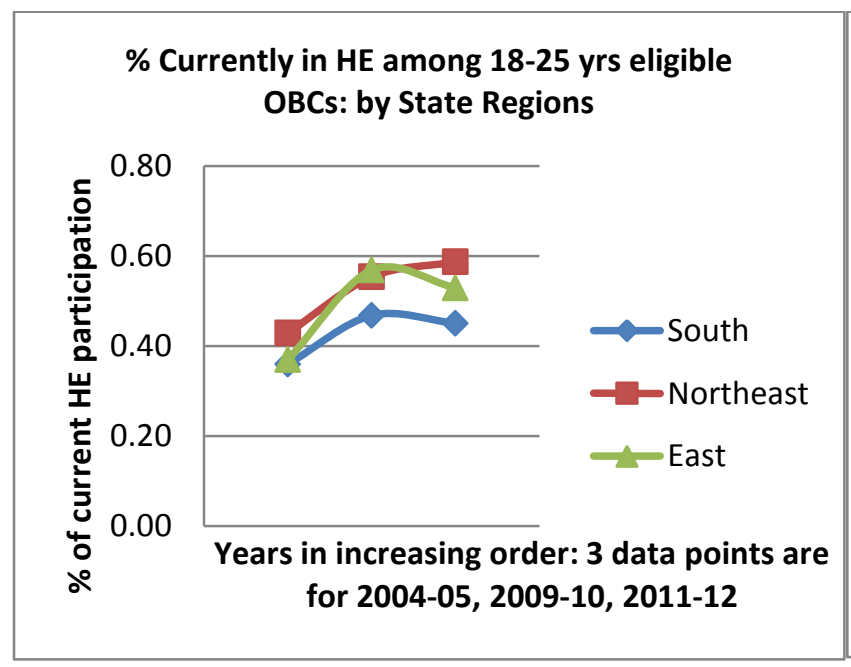

figure $2 \mathrm{~A}$

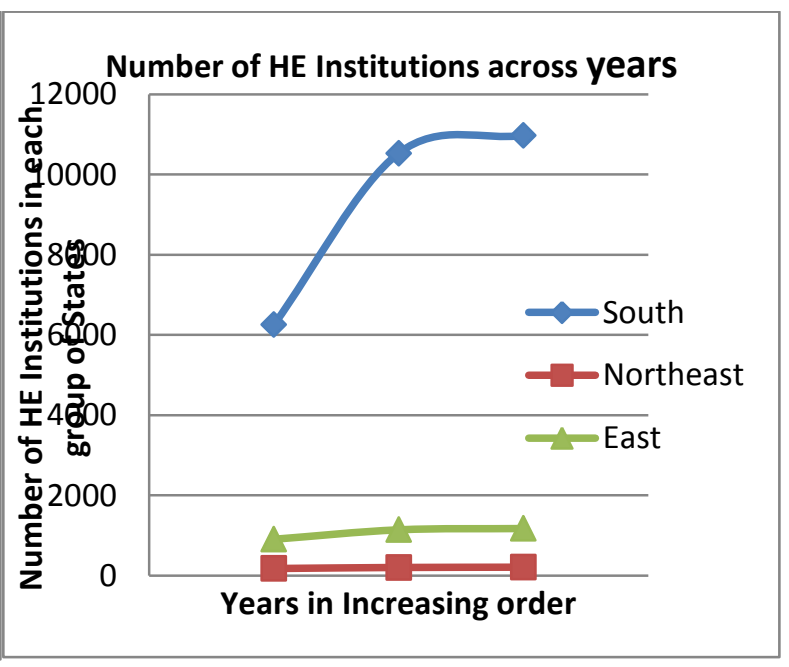

figure 2B 
Appendix Table A1 Panel A: Descriptive Statistics of Treatment and Control for all region sample

\begin{tabular}{|c|c|c|c|c|c|c|c|c|}
\hline \multirow[b]{2}{*}{ Variable } & \multicolumn{4}{|c|}{ Treated cohort: $18-23$} & \multicolumn{4}{|c|}{ Control cohort: $24-29$} \\
\hline & $\begin{array}{l}\text { OBC } \\
\text { Obs }\end{array}$ & Mean & $\begin{array}{l}\text { Others } \\
\text { Obs }\end{array}$ & Mean & $\begin{array}{l}\text { OBC } \\
\text { Obs }\end{array}$ & Mean & $\begin{array}{l}\text { Other } \\
\text { Obs }\end{array}$ & Mean \\
\hline HE participation & 6940 & 0.57 & 6234 & 0.59 & 4708 & 0.07 & 5123 & 0.06 \\
\hline Male $(=1)$ & 6948 & 0.55 & 6246 & 0.56 & 4708 & 0.57 & 5123 & 0.53 \\
\hline Age & 6948 & 20.33 & 6246 & 20.49 & 4708 & 26.13 & 5123 & 26.18 \\
\hline Age square & 6948 & 416.02 & 6246 & 422.57 & 4708 & 685.31 & 5123 & 688.16 \\
\hline Dependent ratio & 6948 & 0.27 & 6246 & 0.25 & 4708 & 0.26 & 5123 & 0.25 \\
\hline Very poor & 6948 & 0.01 & 6246 & 0.00 & 4708 & 0.01 & 5123 & 0.00 \\
\hline Vulnerable & 6948 & 0.10 & 6246 & 0.05 & 4708 & 0.08 & 5123 & 0.05 \\
\hline Middle class & 6948 & 0.45 & 6246 & 0.37 & 4708 & 0.41 & 5123 & 0.33 \\
\hline High income & 6948 & 0.44 & 6246 & 0.58 & 4708 & 0.50 & 5123 & 0.62 \\
\hline Head prim or below & 6948 & 0.41 & 6246 & 0.25 & 4708 & 0.27 & 5123 & 0.18 \\
\hline Head Sec or below & 6948 & 0.32 & 6246 & 0.34 & 4708 & 0.31 & 5123 & 0.30 \\
\hline HS head & 6948 & 0.15 & 6246 & 0.20 & 4708 & 0.19 & 5123 & 0.19 \\
\hline Grad head & 6948 & 0.13 & 6246 & 0.21 & 4708 & 0.23 & 5123 & 0.33 \\
\hline Female head & 6948 & 0.12 & 6246 & 0.11 & 4708 & 0.12 & 5123 & 0.10 \\
\hline Rural House & 6948 & 0.58 & 6246 & 0.48 & 4708 & 0.47 & 5123 & 0.41 \\
\hline $\begin{array}{l}\text { Increase State gov HE 04- } \\
11 \\
\text { Increase State pvt HE 04- } \\
11\end{array}$ & $\begin{array}{l}6948 \\
6948\end{array}$ & $\begin{array}{l}78.41 \\
790.41\end{array}$ & $\begin{array}{l}6246 \\
6246\end{array}$ & $\begin{array}{l}68.35 \\
662.91\end{array}$ & $\begin{array}{l}4708 \\
4708\end{array}$ & $\begin{array}{l}78.04 \\
803.17\end{array}$ & $\begin{array}{l}5123 \\
5123\end{array}$ & $\begin{array}{l}63.32 \\
627.29\end{array}$ \\
\hline
\end{tabular}

Note: The sample consists of all 18-29 years old eligible (completed HS) OBC and general population, residing in one of the 21 states that could be divided into four regions. For the household where head's education is missing is not part of the sample. 
Appendix Table A1 Panel B: Descriptive Statistics of Region wise sample

\begin{tabular}{|l|ll|lll|l|l|ll|ll|}
\hline \multirow{2}{*}{ Variable } & \multicolumn{3}{|l}{ All regions } & \multicolumn{2}{l}{ South } & \multicolumn{2}{l|}{ East } & Northcentral & Northeast \\
\cline { 2 - 10 } & Obs & Mean & Obs & Mean & Obs & Mean & Obs & Mean & Obs & Mean \\
\hline HE participation & 23005 & 0.37 & 943 & 0.43 & 2635 & 0.38 & 12932 & 0.38 & 943 & 0.43 \\
OBC & 23025 & 0.51 & 948 & 0.54 & 2640 & 0.25 & 12941 & 0.43 & 948 & 0.54 \\
Treat & 23025 & 0.59 & 948 & 0.54 & 2640 & 0.56 & 12941 & 0.59 & 948 & 0.54 \\
Male & 23025 & 0.55 & 948 & 0.55 & 2640 & 0.56 & 12941 & 0.57 & 948 & 0.55 \\
Age & 23025 & 22.76 & 948 & 23.11 & 2640 & 23.14 & 12941 & 22.77 & 948 & 23.11 \\
& & & & & & & & & & \\
Age square & 23025 & 528.58 & 948 & 544.35 & 2640 & 546.24 & 12941 & 528.68 & 948 & 544.35 \\
Dependent ratio & 23025 & 0.26 & 948 & 0.26 & 2640 & 0.23 & 12941 & 0.28 & 948 & 0.26 \\
Very poor & 23025 & 0.01 & 948 & 0.00 & 2640 & 0.00 & 12941 & 0.01 & 948 & 0.00 \\
Vulnerable & 23025 & 0.07 & 948 & 0.10 & 2640 & 0.08 & 12941 & 0.08 & 948 & 0.10 \\
Middle class & 23025 & 0.39 & 948 & 0.53 & 2640 & 0.49 & 12941 & 0.39 & 948 & 0.53 \\
High income & 23025 & 0.53 & 948 & 0.37 & 2640 & 0.43 & 12941 & 0.51 & 948 & 0.37 \\
& & & & & & & & & & \\
Head prim or below & 23025 & 0.29 & 948 & 0.26 & 2640 & 0.26 & 12941 & 0.27 & 948 & 0.26 \\
Head Sec or below & 23025 & 0.32 & 948 & 0.34 & 2640 & 0.37 & 12941 & 0.32 & 948 & 0.34 \\
HS head & 23025 & 0.18 & 948 & 0.18 & 2640 & 0.16 & 12941 & 0.18 & 948 & 0.18 \\
Grad head & 23025 & 0.21 & 948 & 0.22 & 2640 & 0.22 & 12941 & 0.23 & 948 & 0.22 \\
Female head & 23025 & 0.11 & 948 & 0.09 & 2640 & 0.11 & 12941 & 0.10 & 948 & 0.09 \\
Rural House & 23025 & 0.49 & 948 & 0.52 & 2640 & 0.54 & 12941 & 0.52 & 948 & 0.52 \\
Increase State gov & & & & & & & & & & \\
HE 04-11 & 23025 & 72.35 & 948 & 3.59 & 2640 & 14.48 & 12941 & 47.61 & 948 & 3.59 \\
Increase State pvt & 23025 & 722.93 & 948 & 2.85 & 2640 & 95.92 & 12941 & 579.49 & 948 & 2.85 \\
HE 04-11 & & & & & & & & & \\
\hline
\end{tabular}

Note: The sample consists of all 18-29 years old eligible (completed HS) OBC and general population, residing in

one of the 21 states that are part of this study. For the household where head's education is missing is not part of the sample. 
Table A2: DD estimation of year 2011-12 by State group: Dependent variable is HE Enrollment

\begin{tabular}{|c|c|c|c|c|}
\hline & South & East & Northeast & Northcentral \\
\hline $\mathrm{OBC}$ & -0.004 & 0.022 & $-0.07^{*}$ & $0.037^{* *}$ \\
\hline treat & $0.115^{* * *}$ & $0.208 * * *$ & $0.291 * * *$ & $0.207 * * *$ \\
\hline OBC\#treat & -0.03 & 0.021 & -0.037 & -0.027 \\
\hline Male & $0.06 * * *$ & 0.023 & -0.018 & $0.053^{* * *}$ \\
\hline Age & $-0.424 * * *$ & $-0.403 * * *$ & $-0.364 * * *$ & $-0.286 * * *$ \\
\hline Age square & $0.008 * * *$ & $0.007 * * *$ & $0.006 * *$ & $0.005^{* * *}$ \\
\hline Dependent ratio & -0.074 & -0.068 & 0.021 & -0.035 \\
\hline Very poor & -0.028 & -0.157 & $-0.545^{* *}$ & $-0.251 * * *$ \\
\hline Vulnerable & $-0.107^{* *}$ & $-0.095 * *$ & -0.085 & $-0.043^{*}$ \\
\hline Middle class & $-0.052 * *$ & $-0.063^{* *}$ & -0.067 & $-0.028 * *$ \\
\hline Sec or below head & $0.073 * *$ & $-0.049 *$ & $-0.137^{*}$ & $0.037^{*}$ \\
\hline HS head & $0.055^{*}$ & 0.029 & $-0.132 * *$ & 0.021 \\
\hline Grad head & $0.125 * * *$ & 0.019 & -0.075 & $0.098 * * *$ \\
\hline Female head & 0.006 & -0.008 & -0.037 & 0.011 \\
\hline Rural & 0.019 & -0.017 & -0.059 & -0.02 \\
\hline Increase of state_govt_he 0411 & $0 *$ & $-0.041 * *$ & 0.004 & 0 \\
\hline Increase of state_pvt_he0411 & $0 *$ & $0.006 * *$ & $-0.026 *$ & $0 * * *$ \\
\hline$R^{2}$ & 0.37 & 0.45 & 0.54 & 0.33 \\
\hline$N$ & 6,495 & 2,635 & 943 & 12,932 \\
\hline
\end{tabular}

Note: The sample consists of all 18-29 years old eligible (completed HS) OBC and general population, residing in one of the 21 states that are part of this study. For the household where head's education is missing is not part of the sample. 
Table A3: Test of Robustness of DD results with different years Panel A: Placebo year is 2004-05

\begin{tabular}{lllll}
\hline & South & East & Northeast & Northcentral \\
\hline 1.obc & $0.031^{* *}$ & 0.024 & -0.026 & 0.011 \\
1.treat & $0.121^{* * *}$ & 0.076 & -0.003 & $0.097 * * *$ \\
1.obc\#1treat & $-0.113^{* * *}$ & -0.051 & $0.167 * *$ & -0.013 \\
& & & & \\
$R^{2}$ & 0.30 & 0.37 & 0.20 & 0.27 \\
$N$ & 5,356 & 2,452 & 978 & 11,484 \\
\hline
\end{tabular}

Panel B: Placebo year is 2009-10

\begin{tabular}{lllll}
\hline & South & East & Northeast & Northcentral \\
\hline 1.obc & -0.004 & $0.052^{* *}$ & $0.057^{*}$ & 0.021 \\
1.treat & 0.049 & $0.168^{* * *}$ & 0.133 & $0.205^{* * *}$ \\
1.obc\#treat & 0.030 & -0.014 & $0.119^{*}$ & -0.032 \\
& & & & \\
$R^{2}$ & 0.37 & 0.52 & 0.40 & 0.34 \\
$N$ & 6,022 & 2,324 & 1001 & 11,272 \\
\hline
\end{tabular}

Panel C: DD results of Year 2011-12 as copied from Table 6 for comparison with Placebo years

\begin{tabular}{lllll}
\hline & South & East & Northeast & Northcentral \\
\hline 1.obc & -0.004 & 0.022 & $-0.07 *$ & $0.037 * *$ \\
1.treat & $0.115^{* * *}$ & $0.208 * * *$ & $0.291 * * *$ & $0.207 * * *$ \\
1.obc\#treat & -0.03 & 0.021 & -0.037 & -0.027 \\
& & & & \\
$R^{2}$ & 0.37 & 0.45 & 0.54 & 0.33 \\
$N$ & 6,495 & 2,635 & 943 & 12,932 \\
\hline$* p<0.1 ; * * p<0.05 ; * * * p<0.01$ & & &
\end{tabular}

